\title{
Práticas aventureiras e situações de risco no voo livre: uma análise a partir do conceito de redoma sensorial
}

\author{
Jairo Antônio da Paixão ${ }^{1}$ \\ Vera Lucia de Menezes Costa ${ }^{2}$ \\ Ronaldo Eugénio Calçada Dias Gabriel ${ }^{3}$ \\ Marizabel Kowalski ${ }^{4}$ \\ ${ }^{1}$ Doutorando em Ciência do Desporto pela Universidade de Trás-os-Montes \& Alto \\ Douro, Portugal \\ ${ }^{2}$ Programa de Pós-Graduação em Educação Física da Universidade Gama Filho, RJ. \\ Brasil \\ ${ }^{3}$ Department of Sport Science da Universidade de Trás-os-Montes \& Alto Douro, \\ Portugal \\ ${ }^{4}$ Departamento de Educação Física da Universidade Federal de Viçosa, MG, Brasil
}

\begin{abstract}
Resumo: O presente estudo analisa situações de risco na prática de voo livre por intermédio do conceito de redoma sensorial. A amostra foi constituída de 19 (dezenove) praticantes da modalidade de parapente, com média de idade de 31 (trinta e um) anos, considerou-se o desvio padrão com significância $><0,05 \%$. A partir do método de estudo descritivo-exploratório foi possível verificar que o domínio da técnica e o uso de equipamentos adequados, apesar de imprescindíveis não garantem o êxito desses atores. Muitas vezes, as situações de risco vivenciadas agregam num primeiro momento um verdadeiro arcabouço de elementos sensoriais extraordinários. No entanto, as vivências diárias numa dada modalidade podem levar à banalização desses elementos por parte do praticante, transformando-se em elementos sensoriais ordinários. Essa situação poderá implicar negativamente na prática das modalidades de esporte de aventura como, por exemplo, a manutenção da integridade física e emocional do praticante.
\end{abstract}

Palavras-chave: Risco. Parapente. Redoma sensorial.

\section{Adventurous practices and risk situations in the free flight: an analysis starting from the concept of sensorial dome}

\begin{abstract}
This study analyzes the risk situations in the practice of free flight through the concept of sensorial dome. The sample consisted of 19 (nineteen) practitioners of the paragliding, with the age middle was 31 (thirty one) years old and the arithmetic absolute media considered by researches was $><0.05 \%$. From the method of descriptive exploratory study was concluded that that the field of technology and use appropriate equipment, though not essential guarantee the success of these actors. In the major of time, the risky situations experienced in the adventure sport, join at a first moment a true outline of extraordinary sensorial elements. However, the daily experiences observed in a given kind can take to the banalization of those elements by the apprentice, becoming ordinary sensorial elements. Such change can present implications in and for the practice of the adventure sport kinds in natural environment like, for instance, the apprentice's physical and emotional integrity.
\end{abstract}

Key Words: Risk. Paragliding. Sensorial dome.

\section{Introdução}

As atividades físicas e esportivas denominadas esporte de aventura e risco na natureza vêm despertando a atenção das pessoas, aumentando-lhes cada vez mais a popularidade no universo esportivo (MARINHO; BRUHNS, 2003). Termos como risco, aventura, adrenalina e superação dos próprios limites, passaram a fazer parte da linguagem do cotidiano, trazendo à mente as sensações fortes, as imagens de risco e emoções vividas por aqueles que buscam vivenciar 0 desafio e 0 prazer propiciados por esses esportes (COSTA, 1999).

Um dos motivos que vem permitindo uma maior procura e participação nessa vertente esportiva nos diferentes ambientes naturais como terra, água e ar, é o desenvolvimento tecnológico da pesquisa científica, tanto na melhoria da performance técnica como na produção de material, que possibilitam não somente melhorias no desempenho dos praticantes, bem como 
prever, calcular e assim minimizar o risco presente nessas práticas corporais junto a natureza ( $\underline{A B D A L A D}, 2005)$.

Ainda que o esporte de aventura apresente inúmeras possibilidades como prática corporal, é importante ressaltar a necessidade de se considerar que, da mesma forma que elas podem propiciar inúmeros benefícios ao praticante, podem, na mesma proporção, colocar em risco a sua integridade física.

Seja no âmbito da competição ou do lazer, a prática do esporte de aventura implica riscos de diferentes proporções, como quedas, colisões, escoriações, fraturas, afogamentos, congelamentos, mal-estar, entre outros. A realidade mostra que em alguns casos apenas a utilização de equipamentos sofisticados não é suficiente para impedir um sério acidente.

No caso do voo livre, esporte que lida com riscos, segundo Abdalad (2005), é preciso que o praticante domine todas as técnicas de voo, além das informações meteorológicas. Ele deverá perceber e calcular atenciosamente cada possibilidade de risco, para que o programa de voo seja realizado com tranquilidade e the proporcione prazer. Ainda assim, observam-se alguns casos de acidentes, em que o praticante - por imprudência, distração ou falta de controle machuca-se ou até mesmo perde a vida.

\section{O conceito de redoma sensorial}

Ao se considerar o risco como elemento inerente a prática de esporte de aventura na natureza e suas implicações no que se refere a integridade física e emocional do praticante, buscaremos discutir alguns de seus aspectos por intermédio do estudo realizado por Almeida (2008), no qual desenvolve o conceito de redoma sensorial. As incursões realizadas pelo autor nos campos das artes cênicas e circenses balizadas pela filosofia e sociologia, possibilitaram adentrarmos num universo no qual o risco configura-se em meio a rituais, símbolos, busca pelo prazer e da performance nas práticas corporais, nas quais o homem coloca-se em situação-limite.

Partindo do entendimento do conhecimento do senso comum como processo sensorial, o referido autor afirma que a aquisição deste conhecimento pelo homem se processa de forma multisensorial, uma vez que, mobiliza um verdadeiro arcabouço sensorial cotidiano, que através dos canais sensoriais, permite perceber diferentes elementos como sons, odores, tato, cinestesia, noção de distância, temperatura, sabores dentre outros (ALMEIDA, 2008, p. 73).

Assim, como ocorre com o senso comum, que se determina através de um conjunto de sensações conhecidas, confiáveis e dominadas por meio da prática constante, também, a redoma sensorial ordinária forma-se a partir do conjunto de sensações que o indivíduo está acostumado a vivenciar. Assim, ela estrutura-se a partir do arcabouço sensorial básico estabelecido por uma sociedade, num dado momento histórico, como, por exemplo, o grau de limpeza aceitável de uma casa, uma sensação ou um comportamento diante de uma situação conhecida.

Destaca-se que a redoma sensorial ordinária forma-se a partir de elementos, que, pelo fato da constante presença num cotidiano, tornaram-se automáticos, "velhos conhecidos" e, por conseguinte, não mais recebem a devida atenção. Isso decorre do fato de que, na grande maioria das vezes, o indivíduo se esquece de que se encontra envolto por uma redoma.

No que se refere à relação que o indivíduo estabelece no meio social, "... é fundamental que as redomas sensoriais sejam compreendidas como construções sociais, uma vez que são produzidas e compartilhadas por um grande número de pessoas" (ALMEIDA, 2008, p. 76). Desta forma, a visualização de uma redoma sensorial torna-se complexa, haja vista que o individuo, por meio de seus sentidos ordinários deixam de perceber a complexidade das ações praticadas no cotidiano. Como exemplo, este autor menciona a ação de se aguardar um sinal vermelho ficar verde para se atravessar a faixa de pedestres. Na verdade, trata-se de uma ação que reúne uma grande quantidade de códigos sensoriais socialmente produzidos. $O$ autor reforça esta ideia ao afirmar que:

... a lida cotidiana com os sentidos é, na
verdade, uma atividade tão complexa como a
atividade do trapezista. Normalmente não se
percebe isso apenas porque as pessoas de uma
mesma sociedade compartilham as mesmas
redomas e são todas 'trapezistas' também
(ALMEIDA, 2008, p. 83).

Desta forma, percebe-se que não apenas o conhecimento, mas também os sentidos são histórico-culturais. Para perceber esta afirmação basta pensar nas dificuldades enfrentadas por um 
índio ao se movimentar numa grande cidade e nas dificuldades correspondentes de um homem urbano em orientar-se por entre a natureza selvagem. Embora, para cada um desses atores, as redomas sensoriais sejam ordinárias, em contrapartida tratam-se de duas redomas sensoriais ordinárias diferentes, se consideradas as dimensões histórico-culturais. Assim, “ $\ldots$ duas redomas sensoriais ordinárias, produzidas por diferentes sociedades, serão sempre extraordinárias quando vislumbradas uma a partir da outra" (ALMEIDA, 2008, p. 83).

Retomando o exemplo de um índio e de um homem urbano e a permuta de ambientes, eles experimentariam elementos inéditos se comparado àqueles que formam suas redomas sensoriais ordinárias em suas respectivas vidas cotidianas. Disso decorreria que a redoma sensorial ordinária seria substituída por uma redoma sensorial extraordinária. Com isso, aguçar-se-iam os sentidos no indivíduo, o qual indubitavelmente se colocaria em estado de alerta. $O$ autor acrescenta ainda, que 0 deslocamento de apenas um elemento sensorial que compõe uma redoma sensorial ordinária já seria suficiente para que uma nova redoma, no caso, uma redoma sensorial extraordinária surgisse. Assim, uma vez retirados ou deslocados de suas redomas ordinárias de origem, os elementos sensoriais produziriam um evento potencialmente extraordinário.

Nessa perspectiva, o presente estudo teve como objetivo analisar situações de risco vivenciadas por praticantes de voo livre na modalidade parapente a partir do conceito de redoma sensorial.

\section{Prática de esporte de aventura e situações de risco vistas por entre a redoma sensorial}

O conceito de redoma sensorial fornece pistas rumo ao entendimento acerca da prática de esporte de aventura e a busca incessante do praticante por fortes emoções. As diversas modalidades que compõem o esporte de aventura praticado em ambientes naturais distintos como aéreo, aquático e terrestre, reúnem um verdadeiro conjunto de elementos potencialmente extraordinários ${ }^{1}$ como aqueles

\footnotetext{
A utilização do termo "elementos potencialmente extraordinários" se deve ao fato de que ao deparar-se com elementos inéditos (extraordinários) se comparado àqueles que formam as redomas sensoriais ordinárias, ou ainda 0 deslocamento de um elemento sensorial que compõe a
}

ligados ao fator risco. Para além do ambiente natural, no qual se configuram as modalidades de esporte de aventura, o risco e a busca por desafios apresentam-se como uma condição sine-qua-non para a realização dessas práticas desportivas (EWERT, 1985; ELMES; BARRY, 1999; LOEWENSTEIN, 1999).

De acordo com Ashcroft (2001, p.14), desde os tempos clássicos o homem convive com situações de risco ligadas, na maioria das vezes, aos fenômenos naturais e climáticos como verões escaldantes, invernos glaciais e águas gélidas. No entanto, pelo advento dos avanços tecnológicos, observados no final do século XIX e início do XX, o homem se coloca diante de novos riscos.

$\mathrm{Na}$ sociedade ocidental, como nos afirma Costa (1999), a organização social e cultural visa, sobretudo, controlar os perigos que possam prejudicar a coletividade como, por exemplo, aqueles ligados à preservação ambiental através dos riscos de poluição a que somos submetidos. Desta forma, se tem uma situação paradoxal na qual a sociedade globalizada, preocupada em perseguir o risco, busca desenvolver constantemente programas de prevenção e de controle, ao passo que as práticas individuais voltam-se à exposição voluntária de si, ou seja, busca-se vivenciar o risco através de formas variadas, por meio do esporte de aventura e risco calculado na natureza.

Em alguns casos, dependendo do tipo de ocupação profissional, esses riscos constituemse como parte inevitável do trabalho (ASHCROFT, 2001). De uma maneira geral, o risco, como afirma Le Breton (2004), mantêm-se num horizonte insuperável da condição humana. Estudiosos como Beck (1993); Giddens (1991; 2001); Sánchez (1996) ao discutirem aspectos pertinentes a sociedade apresentam como eixo comum em suas discussões o emprego da expressão sociedade do risco para conceituar a sociedade contemporânea. Daí é possível afirmar que o risco constrói-se nas condições sociais e culturais de cada comunidade, incorpora fragilidades e varia-se em função de tempo e de lugar.

redoma sensorial ordinária já seria suficiente para que uma nova redoma, ou seja, uma redoma sensorial extraordinária surgisse (ALMEIDA, 2008). 
Assim, ao se considerar o risco presente na prática das diversas modalidades de esporte de aventura na natureza faz-se necessário ponderar aspectos como a manutenção da integridade física e emocional do praticante, o condicionamento físico, o desenvolvimento de habilidades necessárias à modalidade de aventura em questão, equipamentos e vestimentas apropriadas, uma adequada hidratação e ingestão de nutrientes, a existência ou não de equipes de resgate e socorro e as características do ambiente natural no qual ocorrerá a modalidade em questão, dentre outros.

No entanto, estudos nesta área (RYAN, 2003; PAGE; BENTLEY; WALKER, 2003; MORGAN; FLUKER, 2006) demonstram que apesar da necessidade de procedimentos que visam a segurança dos praticantes nas diferentes modalidades de esporte de aventura, não se pode perder de vista que tais procedimentos apresentam-se de forma paradoxal, na qual o controle total dos riscos eliminaria a atratividade e as fortes emoções buscadas pelos praticantes. Nesse sentido, ao se adotar procedimentos no sentido de controlar o risco, há que se considerar variáveis como nível da atividade e habilidades do praticante (WILKS; ATHERTON, 1994; BENTLEY, MACKY; EDWARDS, 2006).

Diferente do que ocorre nas modalidades de esporte clássico como o futsal, vôlei, dentre outros, as práticas ligadas ao esporte de aventura na natureza caracterizam-se pela complexidade de intenções com que se processa sua adesão pelo praticante. Como exemplo, encontra-se a busca voluntária por parte do praticante na contemporaneidade em romper com a redoma sensorial ordinária na qual se encontra envolto 0 seu cotidiano visto na necessidade de experimentação de fortes emoções, de caráter não duradouro. Esta necessidade, na maioria das vezes, é proveniente do aumento do controle emocional na vida das pessoas adultas na sociedade de consumo atual.

Nessa perspectiva, o indivíduo, ao enfrentar o mundo, checa suas marcas, num esforço de concretizar o real que lhe escapa, imprimindo sentidos aos seus limites. A morte que ele se auto-inflige testa 0 valor de sua existência. Paradoxalmente, trata-se de uma sociedade que desfruta de um clima de segurança nunca visto na história ${ }^{2}$. Na ânsia de viver, o indivíduo se auto-impõe a necessidade de dar valor à sua presença no mundo. Insatisfeito, ele se orienta para o lúdico em que ignora o perigo, mas no qual superestima suas capacidades e busca superá-las (COSTA, 1999; LE BRETON, 2004).

Desta forma, o indivíduo busca rebelar-se contra as amarras sociais, por exemplo, a rotina estressante que o cerca na contemporaneidade (ELIAS, 1995; MAFFESOLI, 2001). Nesse contexto, a partir da prática de esporte de aventura o praticante busca em si mesmo, no seu limite físico, a sua referência.

A fim de melhor compreender a situação de risco percebida na prática do esporte de aventura, será considerada a modalidade de montanhismo. De acordo com a Confederação Brasileira de Montanhismo e Escalada a maioria dos acidentes apresenta como causa primária, os comportamentos de risco ${ }^{3}$, ou seja, as ações e ou atitudes do praticante frente ao risco inerente à respectiva modalidade de esporte de aventura. Geralmente, os comportamentos de risco tornamse uma constante na prática desta vertente esportiva, o que contribui para o aumento de acidentes de gravidades variadas para 0 praticante.

Ao se analisar a Pirâmide dos Acidentes, percebe-se que, os comportamentos de risco encontram-se na base. No entanto, ainda que ocupem posição privilegiada nesta escala, os comportamentos de risco por terem se tornado elementos ordinários em momentos que antecedem e mesmo efetivam a prática de uma determinada modalidade de esporte de aventura, algumas vezes não recebem a importância devida por parte dos praticantes.

\footnotetext{
${ }^{2}$ Como afirma Costa (1999), o investimento em prêmios de seguro observado na contemporaneidade é pode ser interpretado como uma forma de reconhecimento da incerteza que envolve o homem. É possível se encontrar infindáveis categorias de seguro. Busca-se desta forma assegurar quase tudo, como por exemplo, automóvel, viagem, como precaução contra incêndio, roubo, invalidez permanente, acidentes, partes do corpo (para o público ligado ao mundo das artes, atletas, dentre outros.) morte, de saúde dentre outros.

3 Dentre os comportamentos de risco encontram-se uma alimentação inadequada, a falta de hidratação, o desconhecimento das técnicas e do ambiente natural, a previsão do tempo, o uso de roupas e equipamentos que não atendem às exigências de uma determinada modalidade de esporte de aventura, haja vista o ambiente natural no qual a mesma será praticada.
} 


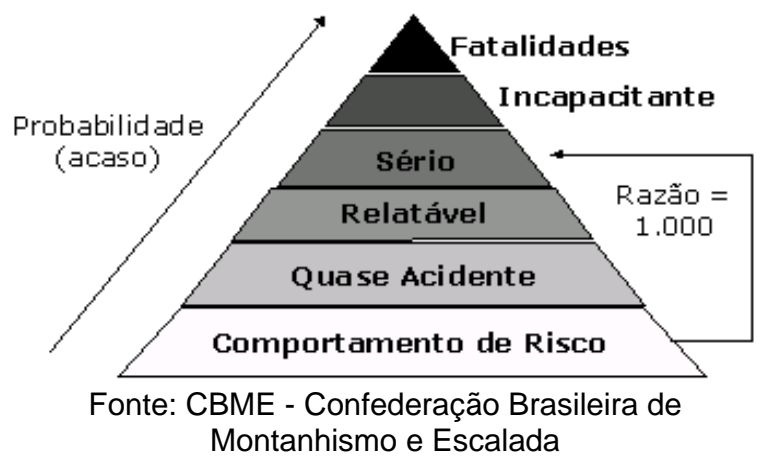

Figura 1. Pirâmide dos acidentes.

Somado a tudo isso, encontra-se ainda o fator "excesso de autoconfiança" que contribui para o aumento da desconsideração de procedimentos, por parte do praticante experiente numa dada modalidade e, que por sua vez, são essenciais à manutenção da segurança do mesmo ( $\underline{\mathrm{CRUZ}}$ VIANA, 1996; BENTLEY; PAGE, 2008). Exemplifica-se esta hipótese 0 fato de um praticante de voo livre que tem o conhecimento de que no momento da prática seu corpo é impulsionado pela gravidade no sentido descendente e pelas correntes de ar quente (térmicas) no sentido ascendente, ainda assim, não levar em consideração as condições atmosféricas antes de lançar-se num voo.

\section{$O$ voo livre}

Entre os relatos a respeito de homens que, através do voo, tentaram libertar-se das amarras terrenas, o mais antigo faz parte de uma lenda da mitologia grega. Tal lenda destaca que $o$ arquiteto Dédalo e seu filho Ícaro, utilizando cera, penas de pássaros e magia, construíram asas para fugir de um intransponível labirinto localizado em Creta. A fuga foi espetacular. Todavia, desrespeitando as regras determinadas por seu pai, ícaro se aproximou do sol e perdeu suas asas - uma atitude imprudente que lhe custou a vida. (POUZADOUX, 2001).

Segundo especificações da Federação Aeronáutica Internacional - FAl, o voo livre é a modalidade esportiva praticada com asa delta ou parapente, na qual o praticante desloca o peso de seu corpo por meio de manobras de uma estrutura rígida por superfícies aerodinâmicas móveis (asa delta), ou até por ausência de estrutura rígida com cabos e outros dispositivos (parapente) (DA COSTA, 2005, p. 479).

Atualmente, a prática do voo livre, aliada aos avanços tecnológicos, pode ser realizada com diferentes objetivos e de diversas formas. Dependendo do nível técnico, o praticante pode utilizar asa delta ou parapente desenvolvidos para propiciar alta, média ou baixa performance. A maneira como ele realizará o voo estará diretamente ligada ao nível de experiência, à habilidade e ao tipo de equipamento utilizado, que nesse caso deverá estar sempre em sintonia com o objetivo desejado (AZEVEDO, 2009). Independentemente do nível de habilidade em que se encontra 0 praticante dessas modalidades, o risco permanecerá como uma espécie de elemento integrador destas.

Ainda que inexista uma estimativa precisa e sua respectiva divulgação pelas associações, federações e confederações sobre acidentes envolvendo praticantes de voo livre, bem como demais modalidades de esporte de aventura no Brasil, nota-se, pelas suas especificidades, que o parapente e a asa delta colocam o praticante em situação de alto risco, pois, uma vez no ambiente aéreo, este se encontra totalmente vulnerável às imprevisibilidades naturais, como, por exemplo, correntes térmicas, direção dos ventos, relevo presente no trajeto do voo, entre outras. Como pratica corporal de aventura na natureza, o vôo livre, agrega uma profusão de elementos como incerteza, risco, desafio, liberdade e aventura (RAMOS, 2003).

\section{Procedimentos metodológicos}

A fim de analisar aspectos ligados às práticas aventureiras dos praticantes de parapente a partir do conceito de redoma sensorial foi realizada uma pesquisa de natureza descritiva (RICHARDSON, 1999; THOMAS; NELSON, 2002). Os participantes deste estudo constituem uma amostra de conveniência, sendo 19 praticantes da modalidade parapente, com média de idade de 31 (trinta e um) anos, considerou-se o desvio padrão com significância $><0,05 \%$, nos quais 14 eram do gênero masculino e 05 do gênero feminino.

Dentre os locais utilizados para a prática do parapente, esses praticantes freqüentam o Pico da Ibituruna na cidade de Governador de Valadares, Minas Gerais. Para a coleta dos dados foram utilizados 02 instrumentos, sendo um questionário semi-estruturado e um questionário de auto-eficácia (Self-efficacy) (SHERER, 1986; BANDURA, 1995; 1997).

O questionário, com questões abertas e fechadas foi estruturado em duas partes, sendo a primeira, constituída por perguntas abertas e 
fechadas com o objetivo de identificar as características dos informantes (formação, tempo de atuação idade, gênero, local de residência e experiência na modalidade de parapente). A segunda parte, constituída por questões abertas, buscou enfocar aspectos ligados à prática e desempenho dos praticantes na referida modalidade esportiva. $\mathrm{Na}$ análise dos dados coletados foi empregada a técnica de análise de conteúdo, proposta por Bardin (2004). Desta forma, inicialmente foi analisado o conteúdo contido nas respostas dos participantes, para então se estabelecer uma identificação de categorias sistemáticas e suas respectivas correlações num momento posterior.

O questionário de auto-eficácia compõe-se de uma escala de 23 itens que busca mensurar a expectativa geral de auto-eficácia do individuo. Para fins de pontuação, traz sete itens $(1,5,9$, $13,17,21,25)$ que são complementares e não contados. Quanto aos itens $(3,6,7,8,11,14,18$, 20, 22, 24, 26, 29, 30) apresentam-se da maneira negativa e por isso são inversamente pontuados, sendo a pontuação total a soma de todos os itens. Antes de pontuar reversamente, as respostas são codificadas como se segue: $A=1$, $B=2, C=3, D=4, E=5$. A pontuação maior representa uma expectativa de auto-eficácia mais elevada.

Vale ressaltar que antes da aplicação dos questionários foi explicado aos participantes 0 objetivo do estudo e que eles tinham liberdade para participar ou não da pesquisa. Assim, todos eles assinaram um Termo de Consentimento Livre e Esclarecido.

\section{Resultados e Discussão}

Com relação ao tempo de experiência com a prática do parapente, o grupo participante do estudo apresentou uma média de 2,3 anos. Em sua totalidade, a prática de tal modalidade ocorre de forma não-sistemática como, por exemplo, nos finais de semana, feriados e períodos de férias. A grande maioria tem curso superior e reside em Minas Gerais em cidades próximas a Governador Valadares, o que facilita ainda mais as práticas no Pico da lbituruna. Quanto à ocupação profissional esta se mostrou bem diversificada evidenciando profissionais liberais, como comerciantes, funcionários públicos bem como professores que atuam em diferentes segmentos da Educação Básica e superior.

Os resultados apontados sobre a auto-eficácia (conforme gráfico 1) mostram uma menor pontuação de 78 pontos e o maior de 105 pontos com desvio padrão de 9,18 e média de 91,47 , o que pode ser traduzido em termos avaliativos, num alto nível de auto-eficácia percebido pelos praticantes no que se refere ao domínio de habilidades e conhecimentos técnicos necessários à prática da modalidade parapente.

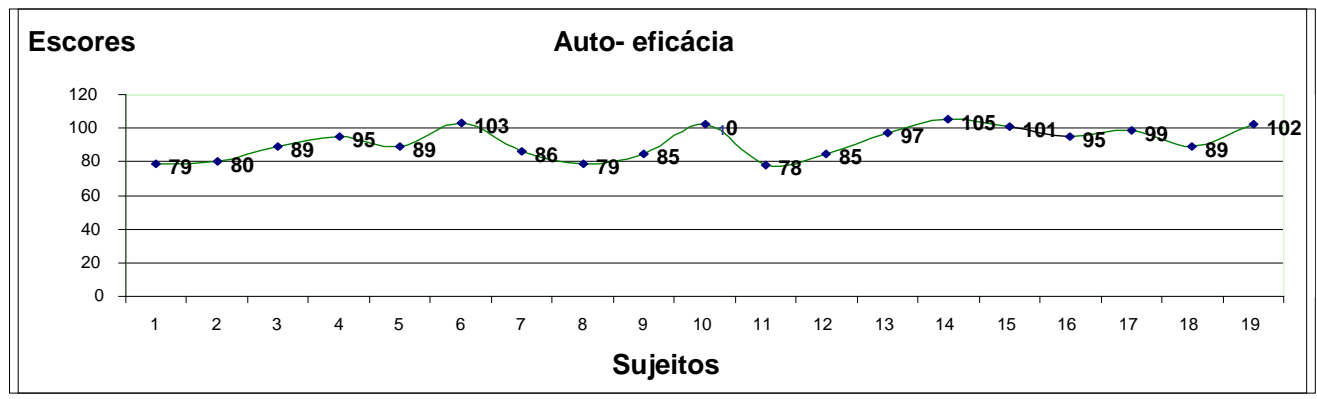

Gráfico 1. Auto-eficácia em praticantes de parapente

O conhecimento e habilidades necessárias à prática do parapente, indubitavelmente perpassa pelas quatro fases do vôo que, segundo Abdalad (2005) envolvem (a) preparação do salto; (b) salto; (c) deslizamento pelos ares; e (d) pouso. De acordo com Pimentel (2008), o êxito em um programa de voo estabelecido pelo praticante dependerá diretamente do que o autor denomina trinômio piloto-equipamento-condição meteorológica. Esse procedimento deverá anteceder as fases do voo, através da incessante checagem dos elementos que compõem o trinômio. 
Quando questionados sobre a ocorrência de acidentes e situações de grande risco, percebeuse que uma parcela significativa dos praticantes entrevistados já havia vivenciado pelo menos uma vez tal experiência. Nesse sentido, os principais motivos apontados são apresentados no quadro 1 a seguir:

Quadro1. Motivos de ocorrência de acidentes e situações de grande risco

\begin{tabular}{llc}
\hline \multicolumn{1}{c}{ Categorias } & $\boldsymbol{F}$ & $\%$ \\
\hline Falta de domínio de conhecimento técnico & 3 & 15,79 \\
Falta de condicionamento físico-motor & 1 & 05,26 \\
Falha no equipamento & 4 & 21,06 \\
Mudança repentina das condições do tempo & 6 & 31,57 \\
Avaliação equivocada e ou descuido quanto & 5 & 26,32 \\
aos riscos inerentes à modalidade & & \\
\hline Total & 19 & 100 \\
\hline
\end{tabular}

Dentre os motivos apontados pelos praticantes para a ocorrência de acidentes e situações de grande risco, as maiores freqüências concentram-se nas categorias "falha no equipamento", "mudança nas condições do tempo" e "avaliação equivocada e ou descuido dos riscos inerentes a prática do parapente". Le Breton (2000), ao discutir a pedagogia do risco, afirma que as experiências adquiridas e a integração gradual das técnicas minimizam as ameaças ou as circunscrevem em pontos onde se exerce vigilância. A menor desatenção pode causar sérios problemas. Há de se considerar ainda que a prática do parapente, estimulada pelo desenvolvimento da pesquisa científica, tanto na melhoria da performance técnica como na produção de material, possibilitam cada vez mais ao praticante vivenciar as fortes emoções dentro de uma margem de controle do risco em que se coloca a cada vez que se lança em um salto. Considerando a freqüência apresentada nas referidas categorias, evidencia-se que o domínio de conhecimentos técnicos e a utilização de equipamentos adequados, apesar de imprescindíveis, nem sempre garantem o êxito do praticante.

Nota-se a existência de uma forma de autossuficiência a partir da qualidade dos materiais e do domínio da técnica pelos praticantes de parapente. Visto dessa forma, o ambiente natural apresenta-se tão somente como um cenário para as práticas aventureiras. Contudo, a natureza é dinâmica e proporciona cada vez mais seu poder de reação e mudanças, ora de forma imperceptível, ora de forma surpreendente.
A avaliação equivocada e ou descuido por parte desse grupo de praticantes pode ser melhor elucidada por meio da teoria da redoma sensorial (ALMEIDA, 2008), a qual em virtude do domínio da técnica, os procedimentos necessários à prática do parapente, bem como as sensações vivenciadas no momento de prática passam de experiências extraordinários para experiências ordinárias na percepção do praticante. $\mathrm{E}$ com isso, uma diminuição no nível de vigília nos comportamentos considerados de risco para esses praticantes.

Nessa perspectiva, as vivências práticas em uma dada modalidade de esporte de aventura parecem conduzir o praticante a um quadro de baixa coesão sensorial dos elementos potencialmente extraordinários como o risco, a vertigem, as fortes emoções dentre outros. Em outras palavras, no âmbito da redoma, os elementos sensoriais extraordinários contidos numa modalidade de esporte de aventura (que por sua vez poderiam vir a aguçar os sentidos do praticante colocando-o em estado de prontidão/alerta numa situação prática) deixariam de existir, uma vez que, pela ação cotidiana, pelo domínio desses elementos por parte deste praticante, eles passariam da a condição de elementos extraordinários para ordinários. Assim, pode-se afirmar que elementos envolvidos numa situação de risco já não colocam o praticante num estado de prontidão/alerta, uma vez estabelecida a redoma sensorial ordinária. É importante ressaltar que não se trata de um suicida, e sim de um individuo que busca vivenciar de maneira prazerosa situações de risco através das modalidades que compõem o esporte de aventura nos diferentes ambientes naturais. 
Após vivenciarem situações de grande risco e acidentes ocorridos na prática de parapente uma parcela expressiva dos participantes, (65\%), alegou que a busca pelas sensações proporcionadas pela prática da referida modalidade em nada foi afetada. E que procuram estar mais atentos e vigilantes nos momentos de prática. Quanto aos demais participantes alegaram que situações envolvendo grandes riscos e acidentes são eventos "normais" quando se pratica uma modalidade de esporte de aventura. No entanto, reconhecem que a adoção de procedimentos, equipamentos adequados bem como a permanente atenção podem atenuar a incidência de acidentes.

Considerando o sentido do risco pelos praticantes de parapente é possível afirmar que 0 risco deliberadamente escolhido para ser vivenciado em modalidades como parapente e asa delta é mais aceitável que o imposto pelas circunstâncias que possam surgir na vida cotidiana. Ainda que a sensação de liberdade e as fortes emoções compensem o risco com que os praticantes irão se deparar no momento da prática, estes não podem ser interpretados como suicidas, e sim como pessoas que gostam de vivenciar situações de risco que lhes causem prazer. Eles se lançam em situações que thes permitem calcular os riscos e Ihes dão condições de controlar o imponderável naquele momento. Le Breton (2000) fala da atitude contra- fóbica, em que um indivíduo, em vez de evitar ou fugir de situações de risco, lança-se em sua direção. Trata-se de uma maneira refinada de esses indivíduos enfrentarem o medo, dissipando-o e sentindo a provisória sensação agradável de tê-lo dominado.

\section{Conclusão}

"Animal arisco, domesticado esquece o risco. Me deixei engar, e até me levar por você... " (Fera ferida. Roberto e Erasmo carlos).

O fragmento desta canção contribui de forma simples e ao mesmo tempo extraordinária para a compreensão e reflexão da temática abordada neste estudo. Desta forma, a domesticação das experiências, efetivada pela passagem do "extraordinário" para o "ordinário", percebidas pelo individuo no decorrer da prática de uma modalidade de esporte de aventura e risco calculado poderá representar o diferencial entre êxito ou comprometimentos de diferentes ordens.
A análise da prática do parapente - uma modalidade que compõe o esporte de aventura e os comportamentos de risco a partir do conceito de redoma sensorial permitiram afirmar que a consideração do risco como elemento constitutivo da respectiva vertente esportiva suscita reflexões.

Esses aventureiros do ar manifestam uma atitude audaciosa para poderem desencadear esse risco, autorizada pela ideia confiante de serem capazes de lançar-se no espaço contra os obstáculos da natureza, associada a um excitante e reconfortante prazer de realizar com sucesso o programa de voo estabelecido.

Para além do domínio da técnica, esperase que praticante adquira uma postura prudente percebendo assim o risco como uma constante em sua prática esportiva, devendo estar atento para calculá-lo, sem expor perigosamente sua vida ou a de outros, e desta forma, vivenciar de forma plena as sensações proporcionadas pela atividade. Durante a realização de práticas esportivas realizadas na natureza, todos os riscos que se apresentam devem ser rigorosamente calculados para que os praticantes possam extrair prazer da atividade. É importante comentar que o perigo permanente, e que em alguns casos a técnica e a coragem dos praticantes não são suficientes para impedir que ocorra um sério acidente.

Sendo assim, parece que o maior desafio a ser vencido pelo praticante no decorrer das vivências nesta vertente de esporte, está em não perder o sentido e as implicações do risco. Esses aventureiros precisam conscientizar-se de que 0 êxito na aventura encontrada em práticas físicas nos diferentes ambientes naturais, precisa ser buscado na mesma proporção de que o são as fortes emoções, a vertigem e o risco.

\section{Referências}

ABDALAD, L. S. Mulheres e vôo livre: o universo feminino nos esportes de aventura e risco. Niterói: Nitpress, 2005.

ALMEIDA, L. G. V. Ritual, risco e arte circense: o homem em situações-limite. Brasília: Editora Universidade de Brasília, 2008.

ASHCROFT, F. M. Life at the extremes: the science of survival. London: Harper Collins, 2001. 
AZEVEDO, S. L. G. Sentidos do risco-aventura socializados nos discursos dos praticantes de voo livre. Dissertação (Mestrado em Educação Física e Cultura) - Programa de Pós-graduação em Educação Física. Universidade Gama Filho, Rio de Janeiro, 2009.

\section{BANDURA, A. Self-efficacy in changing} societies. New York: Cambridge University Press, 1995.

\section{BANDURA, A. Self-efficacy: the exercise of} control. New York: Freeman, 1997.

BARDIN, L. Análise de conteúdo. 4aㅡ ed. Lisboa: Edições 70, 2008.

\section{BECK, U. Risk society: Towards a new} modernity. London: Sage, 1993.

BENTLEY, T. A.; MACKY, K.; EDWARDS, J. Injuries to New Zealanders participating in adventure tourism and adventure sports: an analysis of accident compensation corporation claims. New Zealand Medical Journal, 2006; $119,12-47$

BENTLEY, T. A.; PAGE, S. J. A decade of injury monitoring in the New Zealand adventure tourism sector: a summary risk analysis. Tourism Management, 2008; (29) 857-869.

CBME - Confederação Brasileira de Montanhismo e Escalada. Disponível em: $<$ http://www.cbme.org.br/index.cfm?fuseaction=co nteudo\&secao=25 > . Acesso em 21/08/2008.

COSTA, V. L. M. Esportes de Aventura e Risco na Montanha: Uma Trajetória de Jogo com Limites e Incertezas. Tese de Doutorado. Rio de Janeiro: PPGEF/UGF, 1999.

CRUZ, J. F.; VIANA, M. F. Auto-confiança e rendimento na competição desportiva. Manual de Psicologia do Desporto. Bragança, 1996; p. 265-286.

DA COSTA, L. (org). Atlas do esporte no Brasil: atlas do esporte, educação física e atividades físicas de saúde e lazer no Brasil. Rio de Janeiro: Shape, 2005.

ELIAS, N. O processo civilizador: uma história dos costumes. V.1. Rio de Janeiro: Jorge Zahar, 1995.

ELMES, M.; BARRY, D. Deliverance, denial and the death zone: a study of narcissism and regression in the 1996 Everest climbing disaster. Journal of Applied Behavioural Science, 1999; 35(2): 163-187
EWERT, A. Why people climb: the relationship of participant motives and experience level to mountaineering. Journal of Leisure Research, 1985; 17(3): 241-250.

GIDDENS, A. As conseqüências da modernidade. São Paulo: UNESP, 1991.

GIDDENS, A. Modernidade e identidade. Rio de Janeiro: Jorge Zahar Editor, 2002.

LE BRETON, D. Passions du risque. Paris: Métailié, 2000.

LE BRETON, D. Conduites à risque. Paris: Presses Universitaires de France, 2004.

LOEWENSTEIN, G. Because it is there: the challenge of mountaineering for utility theory. Kyklos, 1999; 52 (3): 315-344.

MAFFESOLI, M. Sobre o nomadismo: vagabundagens pós-modernas. Rio de Janeiro: Recorde, 2001.

MORGAN, D.; FLUKER, M. Risk management for Australian commercial adventure tourism operation. In Y. Mansfeld, \& A. Pizam (Eds.), Tourism, security and safety: From theory to practice. Amsterdam: Elsevier, 2006; p.153-168.

MARINHO, A.; BRUHNS, H. T. Turismo, lazer e natureza. São Paulo: Manole, 2003.

PAGE, S. J.; BENTLEY, T. A.; WALKER, L. Scoping the nature and extent of adventure tourism operations in Scotland: How safe are they?'. Tourism Management, 2003; 26 (3): 381397.

PIMENTEL, G. G. A. Ritos e risco na prática do vôo livre. Revista movimento Porto Alegre, 2008. 14 (03): 13-32.

POUZADOUX, C. Contos e lendas da mitologia grega. São Paulo: Companhia das Leiras, 2001.

RAMOS, J. R. S. Esporte de aventura: um olhar praxiológico a partir dos praticantes de vôo livre da cidade de Niterói. In: Praxiologia motriz no Brasil. Niterói: L. A. Erthal: Faculdades Integradas Maria Tereza, 2003; p. 71-82.

RICHARDSON, R. J. Pesquisa social: métodos e técnicas. $3^{\mathrm{a}}$ ed. São Paulo: Atlas, 1999.

RYAN, C. Risk acceptance in adventure tourism Paradox and content. In WILKS J.; PAGE, S. J. (Eds.), Managing tourist health and safety in the new millennium. Oxford: Pergamon, 2003; p. 55-66. 
SÁNCHEZ, M. R. Los usos sociales del riesgo: el deporte de aventura como configurador de uma ética de la contingencia. In La actividad física y el deporte en un contexto democrático (19761996). Pamplona: Edita: AEISAD, 1996.

\section{SHERER, M. Social foundations of thought} and action. Englewood Cliffs: Prentice Hall, 1986.

THOMAS, J. R.; NELSON, J.K. Métodos de pesquisa em atividade física. $3^{\underline{a}}$ ed. Porto Alegre: Artmed, 2002.

WILKS, J.; ATHERTON, T. Health and safety in marine tourism: A social, medical and legal appraisal. Journal of Tourism Studies, 1994; 11(5): 2-16.

\section{Endereço:}

Jairo Antônio da Paixão

Rua Afonso Pena, 220 centro

Viçosa MG Brasil

36570-000

Telefone : (31) 9125.8292

e-mail: jairopaixa02004@yahoo.com.br

Recebido em: 5 de agosto de 2009.

Aceito em: 13 de maio de 2010.

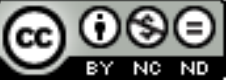

Motriz. Revista de Educação Física. UNESP, Rio Claro, SP, Brasil - elSSN: 1980-6574 - está licenciada sob Licenca Creative Commons 